\title{
What's love got to do with it? Employee engagement amongst higher education workers
}

Orla Byrne and Joe MacDonagh*

Institute of Technology Tallaght, Ireland

Abstract: Employee engagement is an important construct in management research as engaged employees not only perform better in their jobs but also feel happier and more fulfilled in the workplace. Employee engagement is a function of the job resources employees have in coping with their job demands. This paper makes a threefold contribution to the existing engagement literature by: (1) exploring this construct with a sample of third-level academics in the Irish public sector - a relatively unmapped sample in engagement research, (2) identifying organisational support as a key job resource that enables academics to cope with their job demands and (3) proposing that employee engagement reflects how strongly an employee puts his or her heart into work suggesting a reconceptualization of engagement as love. The theoretical and practical implications of these findings are discussed.

Keywords: employee engagement; public sector; job demands-resources model; organisational support; higher education

(C) De Gruyter Open Sp. z 0.0.

\section{INTRODUCTION}

Employee engagement has become a major phenomenon in both academic and business domains over the last two decades as it i suggested that engaged employees not only more productive (Hakanen and Koivumäki, 2014; Harter et al., 2013) but also experience better well-being both inside and outside the workplace (Freeney and Fellenz, 2013a; Hakanen and Peeters, 2015). The potential promise of mutual rewards for both parties in the employment relationship has led to management research devoting much attention to how an engaged workforce can be developed and maintained. However, the majority of this research has been conducted in the private sector (Consiglio et al., 2016; Farndale et al., 2014; Shantz et al., 2016) and academics have highlighted that the literature has paid relatively less attention to understanding the concept of employee engagement in public sector organisations (Jeve et al., 2015; Jones and Sambrook, 2016; Vigoda-Gadot et al., 2012). This is an important research gap as contextual differences exist between the public and private sectors (Knies et al., 2015) that may have implications for the applicability of existing employee engagement models that have been developed and studied in a private sector context. For example, compared to private sector organisations, public sector organisations are traditionally characterised by hierarchical, centralised organisational structures (Boyne, 2002) and a strong trade union presence (Truss, 2013). As such, despite bearing similar levels of responsibility by private sector managers, public sector managers often have little flexibility or scope to effect significant change around rewards and aspects of job design, which have been found to be important antecedents to stimulating high levels of engagement in the private sector (Christian et al., 2011; Saks, 2006). Furthermore, public servants may differ in terms of their motivation, values and expectations (Perry et al., 2010; Willem et al., 2010; Wright, 2007). According to public service motivation theory, people may be drawn to work in the public sector in order to do good for society (Perry et al., 2010). As such, employees whose work involves them providing a public service and contributing positively to society may see their work as a calling that helps them fulfil higher order needs (Perry, 1996; Wright, 2007). Thus, public servants may attach higher levels of perceived meaningfulness to their institutional missions and the work that they do, which may affect the nature and quality of their experiences in the workplace and in turn 
employee engagement levels. Few research studies have investigated how these contextual differences in working conditions and workforce characteristics affect the manner in which employee engagement unfolds in public sector organisations. Byrne et al. (2016) recently highlighted in an engagement study using five different samples that contextual differences can moderate how employee engagement looks and feels to different types of workers. As such, through using quantitative and qualitative methods, the present study seeks to build on these recent findings and bring further clarity to the understanding of the engagement construct by exploring how employee engagement is perceived and experienced by a sample of employees in the Irish public sector and how these experiences are influenced by their perceptions of their working environment.

Additionally, the present study seeks to address a further research gap by focusing on a public sector organisation within the Irish higher education sector. The rationale for concentrating on these higher education workers in particular stems from the lack of engagement research focusing on this area in not only Ireland but also internationally. Most empirical studies tend to explore engagement amongst teachers working at primary and secondary educational levels (Bakker et al., 2007; Hakanen et al., 2006; Klassen et al., 2012; Li et al., 2015; Lorente et al., 2008; Runhaar et al., 2013; Trépanier et al., 2015) compared to the relatively smaller number of studies that have explored engagement levels in higher education institutions - most of which have been in a South African context whose political, economic and educational landscape is not directly comparable to that of Ireland (Barkhuizen et al., 2014; Coetzee and Rothmann, 2005; Rothmann and Jordaan, 2006).

Given the link that engagement has to increase public sector productivity (Hakanen and Koivumäki, 2014) and the Irish government focus on increasing worker productivity (DPER, 2013), it is highly relevant to explore how best to engage these particular workers who comprise a large portion of the Irish public service (CSO, 2016). Additionally, as part of austerity measures introduced in response to the economic crisis, the Irish higher education sector has experienced deep cuts to resources in recent years (Clarke et al., 2015). Academics working in the Irish higher education context have reported a perceived deterioration in working conditions (Clarke et al., 2015), and few empirical studies have explored the implications of these changes for employee engagement levels. Therefore, in order to examine how the unique characteristics of the public sector context may affect the nature and extent of employee engagement, the present study focuses on the specific context of a higher education institution, namely, an Institute of Technology (IoT) in the Irish public sector.

This paper begins by explaining how employee engagement is conceptualised in the academic literature and discussing the associated theoretical framework. The empirical findings are then presented and followed by the implications for theory and practice.

\section{CONCEPTUALISING EMPLOYEE ENGAGEMENT}

Colloquial terms are not commonly used as the basis of research constructs in academia as they can generate multiple interpretations of the same word and lead to conceptual challenges in effectively defining what the phenomenon is (Suddaby, 2010). Employee engagement is one such construct as the multiple understandings of the colloquial term 'engage' has led to various different meanings being attached to the concept both in academia and practice. The ambiguous nature of the concept is further fuelled by the different variations of the term used in the literature such as 'employee engagement', 'work engagement', 'job engagement', 'personal engagement' and 'organisational engagement' (Truss et al., 2014). As a result, after two decades of research, there is no universally accepted definition of engagement (Bailey et al., 2015). Despite the ambiguous use of various different terms in the research literature, the commonality among many of these approaches is that engagement is characterised by the investment of physical, cognitive and emotional resources in the workplace. Thus, engaged employees feel positive and highly focused at work; they care highly about what they do and as such invest greater levels of effort in the workplace (Christian et al., 2011; Kahn, 1990; Saks and Gruman, 2014; Schaufeli et al., 2002; Shuck and Wollard, 2010).

As highlighted by the narrative synthesis of the academic engagement literature of Bailey et al. (2015), some perspectives on engagement are more influential than others. The most widely adopted conceptualisation of engagement in academia is the one proposed by Schaufeli et al. (2002: 74) who used the term 'work engagement' and defined it as a 'positive, fulfilling, work-related state of mind that is characterised by vigour, dedication, and absorption'. Vigour relates to an employee being highly energetic so that they are willing to invest high levels of effort in their work (Schaufeli, 2014). Dedication refers to an employee being strongly involved in their work and 
feeling enthusiastic, inspired and proud about what they do(Schaufeli, 2014). Absorption translates into an employee feeling happily engrossed and concentrated in their work so that the time flies by (Schaufeli, 2014). Schaufeli et al. (2002) suggested that this engaged state of mind is relatively stable and long-lasting and recommended assessing it through their quantitative self-report measure - the Utrecht Work Engagement Scale (UWES) - which has been found to be highly reliable in the Irish public sector (Conway et al., 2015; Freeney and Fellenz, 2013a).

Although Schaufeli et al.'s (2002) conceptualisation of engagement has become the dominant approach in academia (Bailey et al., 2015), as the term 'work engagement' suggests, this conceptualisation narrows the focus of a person's engagement to his or her work tasks (Schaufeli, 2014). Organisational life is broader and more complex than just the relationship individuals have with the work that they do. As such, there are calls for studies to take a wider approach to engagement and further understand the locus of individuals' engagement in the workplace (Bailey et al., 2015; Fletcher and Robinson, 2014). In response to these calls, the present study adopts a multifoci approach to engagement that is receiving increasing empirical attention in the literature (Farndale et al., 2014; Ghosh et al., 2014; Kelliher et al., 2014). The multi-foci approach advocates a pluralist interpretation of engagement whereby an employee is understood to be engaged not only with the work that he or she does but also with the wider organisation in which he or she works (Farndale et al., 2014; Saks, 2006). As such, the multi-foci approach proposes that in addition to work engagement (Schaufeli et al., 2002) there can also be organisational engagement (Farndale et al., 2014; Saks, 2006). Similar to work engagement, organisational engagement is also positioned in the literature as a positive, fulfilling state of mind (Farndale et al., 2014). Employees who are organisationally engaged experience a positive, energetic connection with the organisation they work for and derive fulfilment from the organisation's mission and values (Saks and Gruman, 2014). As such, they are enthusiastic and dedicated towards helping the organisation meet its goals (Farndale et al., 2014). They feel excited to be a member of the organisation and seek to get involved in what is going on within the organisation (Saks, 2006).

Using statistical analyses, previous empirical studies have found that organisational engagement and work engagement are similar yet distinct constructs that are driven by different antecedents and lead to different outcomes (Farndale et al., 2014; Saks, 2006). Intuitively, work engagement is driven by the nature of one's work (Saks, 2006). Job characteristics such as autonomy and interesting, varied tasks that provide opportunities for self-expression and growth are important for determining work engagement levels, whereas organisational engagement is driven by antecedents of a more relational nature such as interpersonal relationships (Saks, 2006). Work engagement has been found to be better at predicting more proximal outcomes at the job level such as active learning and initiative (Farndale et al., 2014), whereas organisational engagement has been found to have stronger positive relationships with broader outcomes such as job satisfaction and organisational commitment than work engagement (Farndale et al., 2014; Saks, 2006). Given the positive relationship in previous studies between organisational engagement and these important job attitudes, it would seem highly useful to study employee engagement in a public sector context given the constraints of working in that sector, such as a traditional bureaucratised public service environment that can potentially frustrate employees and lead to dissatisfaction and turnover. The impetus for taking a multi-foci approach to employee engagement also stems from the fact that in response to long-term resource constraints, employees in different sectors of the Irish public service have taken industrial action in the recent past, including academics (Higgins, 2015, 2016; TUI, 2016). The presence of industrial action after a long period of stability implies high levels of frustration may be present. Thus, it seems particularly relevant to examine not only the relationship academics in the Irish public sector have with their work but also how they currently feel towards their organisation. Having demonstrated the utility of exploring the dichotomy between work engagement and organisational engagement, the next section presents the theoretical framework that guides this study.

\section{Job demands-resources model}

The job demands-resources (JD-R) model (Bakker and Demerouti, 2007, 2014) is the theoretical framework most widely used to explain how and why employees become engaged (Bailey et al., 2015). This theoretical model categorises working conditions as either stressful or helpful, with stressful aspects being called job demands and the helpful aspects being called job resources (Bakker and Demerouti, 2007). Job demands can be sources of stress as they are aspects of the job that require employees to invest sustained effort to deal with them such as a high workload or an unfavourable physical environment (Bakker and Demerouti, 2007). Job resources are helpful as they relate to the aspects of the work environment that employees perceive to be valuable in enabling them to do their job well, such as performance feedback, autonomy and social support (Bakker and Demerouti, $2007,2014)$. The JD-R model argues that when employees have sufficient levels of job resources that help them 
cope successfully with their job demands, it sparks an extrinsic and intrinsic motivational process leading to high engagement levels.

Job resources such as high levels of support and feedback help employees to perform well, thus providing them with the extrinsic motivation to expend effort willingly in their work role (Bakker and Demerouti, 2007). The JD-R model also draws on self-determination theory (Ryan and Deci, 2000) to argue that the presence of job resources helps satisfy employees' basic psychological needs of autonomy, relatedness and competence. Performance feedback and development opportunities thus help employees to feel competent, whilst social support and the ability to make decisions over how the work is carried out help satisfy the need for relatedness and autonomy, respectively. The satisfaction of these basic needs leads to intrinsic motivation (Ryan and Deci, 2000) and hence the willingness to invest energy and effort at work. Therefore, the model argues that job resources stimulate work engagement 'either through the achievement of work goals or the satisfaction of basic needs' (Schaufeli and Taris, 2014: 47), thus causing employees to feel energetic, enthusiastic and absorbed in their work (Schaufeli, 2014). Thus, the main thrust of the model is that a lack of resources to cope with job demands has an adverse effect on intrinsic motivation and extrinsic motivation that lead to employee disengagement.

\section{Job resources in the public sector}

The logic of the JD-R model (Bakker and Demerouti, 2007, 2014) is that if public service workers perceive adequate levels of job resources that enable them to cope with their job demands, they are more likely to be engaged. Although the amount of research on employee engagement in the public sector compared to the private sector is relatively small, the existing empirical research in both the international and Irish public sector contexts has identified some key job resources that help to engage public servants in their work and the organisation as a whole. These resources include perceptions of organisational support and employee voice, and why these resources are important is discussed in the following.

Empirical studies have found that the perceived level of care and support from one's organisation is a key job resource for public service workers (Barkhuizen et al., 2014; Freeney and Fellenz, 2013b; Rothmann and Jordaan, 2006). Organisational support involves various forms of action by line and senior management that signal to employees that their contributions are valued and that the organisation cares for their well-being (Eisenberger et al., 1986). These signals include how appreciative management is of employees' work efforts and how willing they are to help employees overcome the barriers to doing a good job (Eisenberger et al., 1986). In the South African higher education context, it has been found that when academics perceived high levels of organisational support, in the form of a good relationship with one's line manager that was characterised by open lines of communication and recognition for their work efforts, they remained engaged in their work despite experiencing high levels of work overload (Barkhuizen et al., 2014; Rothmann and Jordaan, 2006). However, academics in the Irish public sector have experienced increased teaching contact hours as a result of public sector austerity measures (DPER, 2013), with many finding their workload increasingly demanding (Kenny, 2015). These findings suggest that perceptions of high organisational support, as mentioned by the aforementioned South African research and others, could help Irish public sector academics to cope better with the pace and amount of their work, leading to work engagement.

This study has a multi-foci approach to engagement, which advocates looking at the relationship employees have with both their work and their organisation (Farndale et al., 2014; Saks, 2006). The engagement literature suggests that perceptions of organisational support help determine not only how engaged public servants will be in their work (Barkhuizen et al., 2014; Freeney and Fellenz, 2013b; Rothmann and Jordaan, 2006) but also how engaged they will be in their organisation (Malinen et al., 2013; Reissner and Pagan, 2013). While high levels of organisational support help employees to deal practically with their work roles better, they also help create a better bond between management and employees as employees feel that management understands their work roles and are there for them if they need help (Malinen et al., 2013; Reissner and Pagan, 2013). As management is seen as an agent of the organisation's actions (Eisenberger et al., 1986; Levinson, 1965), having high-quality relationships with management leads to a greater positive connection with the organisation as a whole (Kurtessis et al., 2015) and hence organisational engagement. This suggests that both work engagement and organisational engagement in the public sector are a function of the level of support that employees perceive from their organisation. As a result, we hypothesize that:

Hypothesis 1: Perceptions of organisational support will be positively related to (a) work engagement and (b) organisational engagement. 
A second job resource that has been found to be important for stimulating employee engagement in public sector organisations is employees' perceptions of their ability to participate in decision-making processes and hence influence organisational matters (Conway et al., 2015; Gatenby et al., 2009; Malinen et al., 2013; Reissner and Pagan, 2013). Employees' ability to advance opinions and ideas and feel listened to by management is referred to in the academic literature as the concept of employee voice (Farndale et al., 2011). The magnitude of employee voice needed for driving high engagement levels can be seen in those public sector organisations that had experienced periods of organisational change or uncertainty (Conway et al., 2015; Gatenby et al., 2009; Malinen et al., 2013; Reissner and Pagan, 2013). In the Irish public sector context, Conway et al. (2015) found that giving employees the opportunity to participate in decision-making and contribute ideas and opinions gave them a sense of control over their work. This sense of control helped employees to deal with recently increased performance demands that were introduced as part of external productivity measures (DPER, 2013) and led to higher work engagement levels (Conway et al., 2015).

Reissner and Pagan's (2013) qualitative study of a merger between a public and a private sector organisation in the UK found that when management made employees feel valued and included in organisational matters, by seeking their opinions and views and maintaining open lines of communication during the merger, employees responded by becoming engaged with the organisation. Involving employees in matters that affect them signals that the organisation trusts and values public servants' contributions (Eisenberger et al., 1986). In return, they are likely to reciprocate with engagement in their work (Conway et al., 2015) and the organisation (Malinen et al., 2013; Reissner and Pagan, 2013). Therefore, we hypothesize that:

Hypothesis 2: Perceptions of employee voice will be positively related to (a) work engagement and (b) organisational engagement.

\section{METHODOLOGY}

In order to test the proposed hypotheses, quantitative data in the form of a self-report survey was collected from full-time academics working in an loT. However, numbers can only tell so much about a person's engagement in the workplace, and so, in order to fully understand the concept of employee engagement, the sole use of statistical measures is not enough (Bailey et al., 2015; Jones and Sambrook, 2016). Hearing a lecturer describe in person how they connect with their academic area, students and the institute in which they work cannot be fully appreciated in a questionnaire alone. These are more subjective issues that can be more fully appreciated by hearing employees' stories. Tone of voice and choice of language can help establish the depth and complexity of employees' enthusiasm and dedication towards their work and organisation. These nuances can be understood more fully by delving deeper into employees' experiences through the collection and analysis of qualitative data. Given the limitations of solely using quantitative methods and the calls for engagement to be explored qualitatively (Bailey et al., 2015; Jones and Sambrook, 2016), the quantitative survey was complemented with qualitative methods in the form of five individual indepth interviews and one focus group. The focus group was attended by seven academics, and this was a rich means by which to understand the full scope and nature of engagement for these public sector workers. The next section describes the sample of academics used in the present study and the rationale behind the methodological decisions.

\section{Sample and methods}

Quantitative survey data was collected within an loT from full-time members of academic staff who were members of the Teachers Union of Ireland (TUI). The TUI represented $70 \%$ of lecturers in the loT sector (Kenny, 2015) in 2014 and $84 \%$ of the lecturers in the current loT at the time of the study as out of approximately 200 full-time academic staff, 168 of these academics were members of the TUI. As such, partnering with the TUI would provide access to a large representative sample of academics. All 168 academics were emailed a link to an online selfreport survey, which was also made available in the paper format. A total of 81 academics completed the survey, resulting in a response rate of $48 \%$. In all, $57 \%$ of respondents were males and $43 \%$ were females. To complement the quantitative data, members of the TUI in this specific loT also participated in individual in-depth interviews $(n=5)$ and one focus group $(n=7)$. Individual interviews were carried out first to explore the in-depth, personal, physical, emotional and cognitive experiences that lecturers have in the workplace. The administration and analysis of the quantitative survey revealed that further qualitative research was warranted to extract meaning behind the 
numbers and probe important issues that arose in more depth. A focus group was chosen in order to capitalise on the qualitatively different group dynamic that can help the researcher to identify possible subtleties in meaning that emerge discursively. These qualitative methods helped explore the depth and complexity of this particular sample of academics' work and organisational levels and perceptions of job resources.

The present study anticipated that given the austerity cutbacks in the loT sector and the recent finding that academics in the loT sector were at high risk of work-related stress (Kenny, 2015), it was likely that academics in the chosen institute might have a less positive outlook on organisational life. As a result, judgment sampling (Malhotra and Birks, 2006; Saunders et al., 2009) was used to select lecturers to participate in the qualitative phases who would not only be particularly informative in order to answer the research questions but also be able to give a fair and balanced account of their experiences within the institute.

\section{Quantitative measures Work engagement}

The 9-item version of the UWES (Schaufeli et al., 2002) was used to measure work engagement. A sample item is ' am enthusiastic about my job'. In line with the recommendations from the developers of the scale, a 7-point frequency response scale was adopted ranging from 0 (never) to 6 (always). The value of Cronbach's alpha was 0.88 .

\section{Organisational engagement}

The 5-item scale of Farndale et al. (2014) was used to measure organisational engagement. The items were measured on a 5-point Likert scale from 1 (strongly disagree) to 5 (strongly agree). A sample item is 'One of the most exciting things for me is getting involved with things happening in this organisation'. The value of Cronbach's alpha was 0.90 .

\section{Job resources}

\section{Organisational support}

The resource of organisational support was operationalised using the 8-item perceived organisational support (POS) scale developed by Eisenberger et al. (1986). A sample item is 'My organisation really cares about my wellbeing'. A 7-point Likert scale from 0 (strongly disagree) to 6 (strongly agree) was used, and the value of Cronbach's alpha was 0.83 .

Employee voice

The 4-item 'Employee Voice' scale developed by Conway et al. (2015) was used to operationalise this job resource. The scale uses a 5-point Likert scale from 1 (strongly disagree) to 5 (strongly agree) and has been found to be highly reliable in the Irish public sector context (Conway et al., 2015). A sample item is 'I have good opportunities to participate in decisions that affect me'. The value of Cronbach's alpha was 0.85 .

\section{Demographics}

Demographic details were collected as part of the self-report survey to see if these make a difference to perceptions of job resources and engagement levels. Information was collected regarding gender, age, organisational tenure, educational attainment, employment contract, grade and academic school.

Having detailed the measures and demographic variables used to develop the survey, the quantitative results are presented first and then the qualitative findings are discussed to show their relationship to the quantitative results and help explain the meaning behind the statistics.

\section{QUANTITATIVE RESULTS}

The present study aimed to explore the work and organisational engagement levels of a particular sample of academics working in the Irish public sector. As shown in Table 1, which presents the descriptive statistics for all the study variables, work engagement scores were relatively high with a mean of 4.07 and a standard deviation (SD) of 0.991. The UWES used in the present study measures how frequently employees feel engaged, and on this scale, this score is equivalent to academics feeling engaged in their work at least once a week (Schaufeli and Bakker, 2003). Thus, the majority of these lecturers enjoy a good relationship with their work as they regularly experience feelings of positive fulfilment. 
Table 1. Descriptive statistics, bivariate correlations and reliabilities

\begin{tabular}{|c|c|c|c|c|c|c|}
\hline No. & Variable & Mean & SD & 1 & 2 & 3 \\
\hline 1 & Work engagement & 4.07 & 0.991 & $(0.88)$ & & \\
\hline 2 & Organisational engagement & 3.01 & 0.958 & $0.569^{\star *}$ & $(0.90)$ & \\
\hline 3 & POS & 2.21 & 1.362 & $0.441^{* *}$ & $0.670^{\star *}$ & $(0.83)$ \\
\hline 4 & Employee voice & 2.32 & 0.913 & 0.131 & $0.459 * \star$ & $(0.85)$ \\
\hline
\end{tabular}

The value of Cronbach's alpha is reported in parentheses. ${ }^{*}$ Correlations are significant at 0.01 level. $\mathrm{POS}=$ perceived organisational support; $\mathrm{SD}=$ standard deviation.

In contrast to the measure of work engagement used in this study, the chosen organisational engagement scale (Farndale et al., 2014) measured the intensity of academics' feelings towards the organisation rather than the frequency of their organisational engagement. The mean score for organisational engagement was 3.01 with an SD of 0.958 . As this overall score sits on the neutral point of the response scale and the SD shows that there were some variations in the extent to which these academics' experienced a positive or negative connection with the organisation, the frequency of scores for each of the five response points was further analysed (Table 2).

Table 2. Organisational engagement scores in percentages

\begin{tabular}{lc}
\hline Scoring categories & \% \\
\hline \hline Strongly disagree & $12.3 \%$ \\
Disagree & $25.9 \%$ \\
Neither agree nor disagree & $45.7 \%$ \\
Agree & $12.3 \%$ \\
Strongly agree & 2.5 \\
\hline
\end{tabular}

Table 2 shows that while the majority of participants appeared to be ambivalent about their connection with the organisation, $38.2 \%$ reported having a poor relationship with the organisation and only $14.8 \%$ of lecturers felt that they have a positive relationship with the organisation. These statistical results show that although these academics frequently felt engaged in their work, they reported a poorer relationship with the institute in which they work, which suggests that the relationship they have with the organisation is not as strong as their connection with their work.

Few significant relationships were found between the demographic data and both types of engagement. A significant moderate association was found between organisational engagement and gender $(r=0.29, p<0.05)$. In particular, the results suggested that male lecturers were more likely to experience lower levels of organisational engagement than female lecturers, which suggests that there is a certain cohort of males in the institute who are relatively more disengaged. The relationships between perceptions of job resources and work engagement and organisational engagement are explicated using the results of the hypotheses testing.

In order to test the hypotheses, multiple regression analyses were conducted, and the results are presented in Table 3. Job resources of POS and employee voice were regressed simultaneously onto the work and organisational engagement variables. As shown in Table 3, POS was the only job resource that was found to be significantly positively related to both work $(B=0.60, p<0.01)$ and organisational engagement $(\beta=0.65, p<0.01)$, providing support for hypothesis $1 \mathrm{a}$ and $\mathrm{b}$. Employee voice was not significantly related to either work or organisational engagement, and so, hypothesis $2 a$ and $b$ is not supported. However, a statistically significant association was found between perceptions of employee voice and the level of education attained $(p<0.05)$. Academics are highly trained, autonomous professionals. Thus, the level of education a lecturer holds appears to shape his or her expectation around the level of influence he or she has in organisational matters and hence impacts his or her perception of employee voice within the organisation.

These results suggest that the extent to which employees perceive that the organisation values their contributions and cares for their well-being has a significant positive effect on the extent they invest greater energy in their work and organisational roles. In contrast to our expectations, perceptions of their ability to influence organisational decisionmaking processes do not appear to foster work or organisational engagement for these particular academics. The significance of these findings is supported and explicated in the qualitative findings, which is presented next. 
Table 3. Multiple regression analyses predicting work and organisational engagement

\begin{tabular}{lcc}
\hline Job resources & Work engagement & Organisational engagement \\
\hline \hline POS & $0.60^{\star \star}$ & $0.65^{\star *}$ \\
Employee voice & -0.018 & 0.059 \\
$R^{2}$ & 0.26 & 0.47 \\
Adjusted $R^{2}$ & 0.24 & 0.46 \\
$F$ & $13.569^{\star \star}$ & $33.332^{\star *}$ \\
\hline
\end{tabular}

Values are standardised $b$ coefficients. ${ }^{*} p<0.01$

POS $=$ perceived organisational support.

\section{QUALITATIVE FINDINGS}

To analyse the qualitative data, thematic analysis (Braun and Clarke, 2006) was used, which is defined as 'a method for identifying, analysing, and reporting patterns (themes) within data' (Braun and Clarke, 2006: 83). Using this analysis technique, two key themes 'love' and 'support' emerged to illustrate the experiences these academics have in the workplace. The theme of 'love' describes the emotional connection these academics have with their work and the organisation, and this connection is important as the level of affection they have for their working lives has implications for their happiness and performance at work. The theme of 'support' concerns academics' perceptions of their working environment and the extent to which they feel valued and appreciated by the organisation. As such, these themes help provide further understanding as to how these academics experience engagement in the workplace and why they choose to engage or disengage.

\section{Love}

Similar to engagement, love is a colloquial term that is difficult to define as it represents many intangible feelings and experiences (Berscheid, 2010; Myers and Shurts, 2002). The term love is traditionally used to describe feelings of affection towards another human being (Berscheid. 2010; Fredrickson, 2013; Rubin, 1970). However, this study builds on other research into the experiences of working in academia that found that academics expressed a great love for their working lives (Clarke et al., 2012). As such, in the present study, the theme of love represents the positive emotional connection participants felt towards their work and their organisation:

I love my subjects and that's why I chose the job because I'm passionate about them (Focus Group Lecturer 5).

I love that about [name of the organisation] [emphasized] (Personal Interview with Lecturer 4).

As noted earlier in this paper, common to the different interpretations of employees, engagement is an investment of physical, cognitive and emotional energy. This theme demonstrates that for these particular academics, engagement is a fundamentally emotional experience. They described the passion and affection they felt for their subjects and lecturing in general, which supports the high work engagement scores found in the quantitative data. Their love for what they do motivated them to invest high levels of care and effort in their work roles. They described how they went to great lengths to prepare for lectures and teach in ways that would be most effective for students:

Trying to teach innovatively, trying to make it interesting, trying to get it across to them, know your material in advance, predict questions they might ask you, the good ones, motivate the ones that have no interest in it (Personal Interview with Lecturer 3).

Love manifests as a caring orientation that can be expressed through acts of sacrifice (Reis et al., 2014; Sabey et al., 2015). This sense of sacrifice came through as one lecturer described how they would fund new resources from their own pocket so as to teach students the most up-to-date material while others recalled their determination to 'perform' for their students and do a good job despite sometimes feeling drained by the cognitively and physically demanding nature of the job: 
It doesn't matter how tired you are, you have to get it from somewhere and go into that class and pretend you have energy (Personal Interview with Lecturer 4).

The love lecturers had towards their work also extended to their organisation. They described that the sense of fulfilment they derived working for an institution enabled them to engage in meaningful work and contribute positively to society:

We're on a mission here to do good. What I mean by that is the college improves things for people, people come in here, education transforms them, and then go out and they get better jobs $1 / 4$ You go into private enterprise you're just making some shareholder richer. There's a social benefit to the job and that makes you feel good about doing it, you can feel that you've done a good job, something good for society. That keeps you here (Personal Interview with Lecturer 3).

However, the quantitative data found poor organisational engagement levels, and this theme helps account for these low scores as some academics described how they had lost the sense of love and affection they once felt towards the organisation:

I think there was a time when I used to have an affinity for [name of the organisation] (Focus Group Lecturer 1).

As the above quote shows, the quality of academics' relationship with the organisation had deteriorated; two main reasons for this were identified, which are explained in the following. First, academics described a perceived incongruence between their values and the organisation's current values that had implications for their identification with the organisation and the fulfilment they derived from it. Autonomy and collegiality are core academic values (Billot, 2010; Winter, 2009), yet the majority of participants in the present study perceived line managers to be exercising greater control over their work and moving away from a collegial style of management. The perceived increase in managerial oversight led participants to feel that they were working in an increasingly structured and standardized environment that was at odds with their personal values and concept of academic identity:

I suppose there was a time I would have considered myself an 'academic'. I feel less and less like an academic. I feel like, a more advanced secondary school teacher. Which I think is not what we're about (Focus Group Lecturer 1).

As management is seen as an agent of the organisation (Eisenberger et al., 1986; Levinson, 1965), the managerial actions had negative implications on the love and affection academics had for the organisation, which, as the quantitative results demonstrated, led to lower levels of organisational engagement. These findings are in line with the higher education literature that suggests that if academics 'see a managerial identity compromising a professional identity of teaching, learning and scholarship', it can lead to feelings of disengagement (Winter, 2009: 124).

As the next theme of 'support' will explicate, another reason for this loss of love related to the perception was that the organisation no longer reciprocated the same level of regard for them. Participants felt that the organisation showed little care and concern for their well-being and did not appreciate their efforts, especially given the fact they were working in an increasingly demanding environment as a result of external productivity measures (DPER, 2013). While love may be expressed through acts of sacrifice (Reis et al., 2014; Sabey et al., 2015) as W.B Yeats pointed out in his 'Easter 1916' poem: 'too long a sacrifice can make a stone of the heart'. Participants felt they had increased their work efforts to maintain high-quality teaching standards in the face of fewer staff numbers and resources, but the perception was that this sacrifice of extra effort and energy was going unrecognised by management, which had led some academics to fall out of love with the organisation. The next theme of support draws out this argument to help explain why these academics felt less engaged with the organisation.

\section{Support}

This theme highlights that the perceived level of support received from academics' direct line manager, such as their head of department (HOD), and also the senior management team (SMT) had a strong influence on their engagement levels. This supports the quantitative results that found that POS was significantly related to 
engagement. The nature of academic work is demanding in that it costs lecturers physical, mental and emotional energy preparing and delivering difficult material to students and motivating them to engage with their subjects. However, academics described how high levels of support from line management helped mitigate the negative impact of job demands, and this support manifested in practical ways such as effectively managing timetables and classroom allocation and also in intrinsic ways such as providing emotional support and understanding when problems arose such as student complaints:

Yeah, I had one or two things that happened with a student over the previous couple of years and it was then that I realized that the manager's actually very supportive. Very supportive and said to me, you know, 'I know you're a good lecturer' and for somebody to say 'I know you're a good lecturer', that means a lot' (Personal Interview with Lecturer 4)

In addition to looking for support from their line managers, participants described how they actively looked for signals (Bowen and Ostroff, 2004; Haggerty and Wright, 2009; Townsend et al., 2012) from the SMT that showed they cared about staff and appreciated their work efforts. However, many academics perceived an absence of signals of support from senior management:

Every year for the last few years, certainly for the last five or six years, I've been listening out at Graduation, you know when they do, when the President's speech, usually the President's speech, and never in the past five years anyway, never have they thanked the academic staff $1 / 4$ I actively listen out for it every year 'cos we used to and that's the thing, we used to (Focus Group Lecturer 2).

Although the academic literature suggests that it is usually the relationship that employees have with their immediate supervisor, rather than senior management, that has more influence on employee behaviour (Purcell and Hutchinson, 2007; Redman and Snape, 2005), this quote shows that perceived levels of support from the top level of management are also important as their actions or inactions can also be viewed as representing the organisation's orientation towards employees. Additionally, academics described how, although their HOD has direct responsibility for them, it was senior management who set the tone in the organisation and ultimately controlled how empowered line managers were to deliver job resources as HODs were perceived to have little influence over academics' workload:

You can go into your head of department and you can complain but they don't have the power to change the fundamentals but the heads of schools are the senior managers and they don't look after us, they don't do the job (Focus Group Lecturer 3).

This quote helps explain the non-significant result for employee voice as a driver of work engagement and organisational engagement as it illustrates how participants feel speaking up about issues will not amount to anything significant for the employees or change anything because of the hierarchical nature of IOTs. Thus, although line managers can provide support at an emotional and practical level, they have little autonomy to effect change at higher levels in the organisation, and thus, support from senior management is also key to fostering and maintaining engagement levels in the public sector.

In summary, these themes have illustrated that lecturers have a great love for what they do. However, in order to maintain the strength of their feelings, they require support from line management and senior management to cope more effectively with the stressful aspects of their work. The next section of this paper discusses the theoretical and practical implications of both the quantitative and qualitative findings.

\section{DISCUSSION}

Using quantitative and qualitative methods, this study set out to understand how a sample of academics in the Irish public sector experience work engagement and organisational engagement and how these experiences were influenced by perceptions of job resources.

First, the findings reveal that the drivers of work engagement and organisational engagement overlap as POS was a significant predictor of both work and organisational engagement. When management signals to lecturers 
that they care about them, appreciate their efforts and is willing to help them overcome barriers to performing well (Eisenberger et al., 1986), lecturers are able to cope with their job demands more effectively and reciprocate by investing greater energy in their work roles leading to higher levels of work engagement. High levels of support from the management also help foster organisational engagement as management is seen as the concrete embodiment of how the organisation regards the employee (Eisenberger et al., 1986; Levinson, 1965), and thus, having better relationships with management leads to a more positive connection with the organisation as a whole (Kurtessis et al., 2015) and hence greater organisational engagement.

The hypotheses concerning the positive relationship between employee voice and both types of engagement were not supported. Thus, for this particular sample of public sector workers, the resource of employee voice, which relates to feeling well informed about what is going on within the organisation and having the opportunity to feed views upwards (Farndale et al., 2011), was neither a significant driver of work nor a significant driver of organisational engagement. This is in contrast to the study of Conway et al. (2015) that, when using the same measure of employee voice, found this job resource to be significantly positively related to work engagement. A possible explanation for the differences in findings may lie in the nature of the public sector sample used in this study. Lecturers are likely to experience higher levels of autonomy and control over their work compared to other public service workers in Ireland given the nature of academia and so have more latitude to shape their job directly (Teichler et al., 2013) by expressing their views on same in different forums. As highlighted in the qualitative analysis, the lack of a significant relationship between employee voice and organisational engagement highlights how the hierarchical and bureaucratic nature of the public sector context (Boyne, 2002) can constrain line managements' ability to provide certain job resources that are important for engaging public servants with the organisation as a whole. This was borne out in the present study as heads of departments were perceived to be unable to effect significant change when employees fed their views upwards.

A second contribution of the present study is that it builds on Byrne et al.'s (2016: 21) suggestion, 'the emphasis on one dimension of engagement, and the intensity and duration of the work may affect how people experience and report their engagement', to demonstrate how the emotional dimensions of engagement emerged as more important for these public service workers. The academics in the present study spoke about their passion for what they do, which suggests that when these particular academics fully invest themselves in their job and their organisation, they experience a much deeper and profound positive emotion than just high levels of vigour or enthusiasm (Schaufeli et al., 2002). While knowing how activated and energetic an employee feels is important, the present study highlights that for public sector workers and the often altruistic nature of their work and institutional missions, understanding the emotional investment they make in the workplace is important to consider when conceptualising engagement. It is the love and passion that the lecturers in the present study felt towards what they do that motivated them to invest high levels of care and effort (Fredrickson, 2013) and maintain this investment of effort even when they felt drained of energy and frustrated at the lack of job resources. They had an enduring positive connection with what they do that went deeper than just a momentary enthusiasm for the task at hand. That is not to say that these feelings of vigour and absorption (Schaufeli et al., 2002) are not important when conceptualising engagement but rather they may be more transient in nature as lecturers described how they felt more excited and enthusiastic when teaching a particular subject or researching a certain area. Therefore, when engaged, these lecturers experienced a state of contentment that was characterised by waves of activation at certain times. As a result, this study highlights that when conceptualising employee engagement, it is important to consider how certain dimensions of engagement may be more important than others in different contexts, and for certain public sectors, worker engagement is perhaps best viewed conceptually as the deep-seated love individuals have for their work and organisation, which is also characterised by special moments of enhanced positivity.

As a result, this study suggests that existing models of engagement that essentially ask employees how often they like their job (Schaufeli et al., 2002) could be more effective at measuring engagement if they reflected a better balance between the emotional and rational nature of employees' decision to engage at work. Although using a frequency-based measure of engagement helps capture the transient nature of their enthusiasm for certain elements of their work that are perceived as more enjoyable than others, also using an intensity-based response scale for some items would more fully capture the emotional connection employees have to their working lives and measure the strength of their love. Few empirical studies have examined the differences between the intensity and frequency of employees' experiences of engagement and the implications for productivity levels (Fletcher and Robinson, 2014). Refining the UWES to look at both experiences would help resolve these tensions. The organisational engagement scale of Farndale et al. (2014) already utilises an intensity scale to assess the strength of an employee's feelings 
towards the organisation. As such, integrating an intensity scale into the UWES measure of engagement would enable future research to make more meaningful comparisons between work and organisational engagement levels and allow further understanding of the dichotomy between both types of engagement.

The present findings demonstrate the value of taking a multi-foci approach towards engagement in a public sector context as they have shown that public servants may have different relationships with the work they do and the organisation for whom they work. In turn, these different relationships have implications for how public servants feel and behave in the workplace. For example, in contrast to their high work engagement scores, these lecturers reported poorer organisational engagement scores and felt less emotionally attached to the organisation compared to their academic work. Given that, in practice, motivating employees to work towards organisational goals is a key objective for human resource (HR) professionals, understanding how public servants' relationships with their organisations unfold is of important concern and suggests that the multi-foci approach to engagement warrants further use in future research in the public sector context.

This study has also highlighted the value of using mixed methods to assess how engaged employees are. The results of the UWES engagement measure in the self-report survey indicated that these lecturers frequently felt engaged in their work, and the qualitative data complemented these statistics by illustrating the love and passion lecturers had for what they do when they spoke. Relying solely on statistical data would have missed the complexity of lecturers' experiences of engagement in the workplace. The present study demonstrates the usefulness of examining employee engagement qualitatively and its complementarity with quantitative data as utilising both types of data allows researchers to get closer to the action in organisational life and better understand the nuances in how employees feel. This study invites future engagement research to draw on both quantitative and qualitative methods when studying employee engagement.

\section{Practical implications}

The present study has highlighted that the care, concern and appreciation that employees receive from management enable them to cope more effectively with the difficult aspects of their job and maintain a positive, fulfilling state of mind in the workplace (Saks, 2006; Schaufeli et al., 2002). There are some practical steps that can be taken to create and maintain a supportive 'engageable' work environment for public sector workers.

Firstly, although line managers have the most direct contact with employees, it is the senior management team who set the tone and context for the organisation (McDermott et al., 2013). Thus, their leadership style and the culture they create shape the behaviour of line managers and ultimately control how empowered they are to deliver job resources. Key to fostering the right kind of culture is selecting public sector managers who recognise the complexity of human behaviour and see the importance of developing high-quality relationships with employees. However, simply putting potentially good managers in place is not enough as organisations need to invest in HR development to ensure that management has the ability to identify the job resources required by employees. In this study, participants described how they actively sought signals of support from management. Therefore, managers should be trained in recognising the explicit and implicit signals they send to employees as a result of their actions in the workplace. Training in altering leadership styles to suit the situation (House and Mitchell, 1974; McDermott et al., 2013) would also be useful as management may need to engage in more explicit signalling of support for certain employees with higher socioemotional needs, and having the ability to recognise this is crucial for maintaining highquality relationships with employees. One way that management can adapt their leadership style to the needs of public servants is by adopting a servant leadership approach (Greenleaf, 1977; Ritz et al., 2012). This management approach seeks to facilitate employees doing the best job they can by recognising their individual differences and focusing on providing them with what they need. This means that management would focus on doing what they can to minimise job demands for employees and providing the job and organisational resources that they need to succeed (Schaufeli, 2015).

In the Irish loT context, line managers are constrained by the external contextual factors such as the Haddington Road Agreement (DPER, 2013) as this agreement adds additional contact hours onto the workload of lecturers. This in turn increases the emotional demands on lecturers as they deal with increased numbers of students through extra classes. However, management can monitor the effect of these quantitative and qualitative demands by making the time to have regular informal chats about how staff are coping and ensuring they have enough emotional support to maintain their well-being. Management could also seek to minimise the negative effect of these additional job demands by building in flexibility such as permitting additional contact hours to be used for research or scholarship purposes.

These steps are just a number of ways that public sector management could seek to create a supportive work 
environment that facilitates engagement with one's job and organisation as a whole. While the findings in this study complement and extend previous engagement research in the Irish public sector (Conway et al., 2015; Freeney and Fellenz, 2013a, b), there are some limitations that must be noted.

\section{Limitations}

First, a cross-sectional research design was utilised, and thus, this study is not capable of assuming cause and effect. Furthermore, the quantitative survey involved self-report measures that can introduce common method bias (Conway and Lance, 2010; Podsakoff et al., 2003). While self-report measures were seen as the most appropriate methodological approach to understand the subjective perceptions of these particular public sector workers and steps were taken to minimise bias such as providing assurances of anonymity and confidentiality (Podsakoff et al., 2003), the possibility of bias cannot be ruled out.

Additionally, a homogenous sample of public sector workers was used in this study as it looked at the experiences of a particular cohort of lecturers in an loT. The nature of academic work differs to the work performed by other employees in the public sector, such as civil servants or even those working in administrative positions in higher education institutions, and so the findings may not be as applicable to other public servants. However, the epistemological aim of this study was not necessarily to generalize the findings to the rest of the Irish public sector but rather to understand the experiences of those in a specific organisation. However, this study has identified important theoretical areas such as organisational support, leadership and culture, which other public sector organisations may seek to explore in their own future studies.

\section{CONCLUSION}

This study has made a number of contributions to existing engagement research. It explored the dichotomy between work and organisational engagement in a public sector context and identified POS as a key job resource that helps drive both types of engagement. Therefore, creating a supportive work environment that involves highquality relationships with management characterised by genuine care and concern for employee well-being and appreciation for their work efforts helps foster work engagement and organisational engagement. Additionally, it has shown that in different work contexts, the physical, cognitive and emotional components of engagement may vary in terms of their contribution to the overall concept of employee engagement. For these lecturers, their emotional connection to the workplace was the key tenet of their engagement, leading to the finding that love for one's job has a lot to do with employee engagement.

\section{References}

Bailey, C., Madden, A., Alfes, K. and Fletcher, L. (2015). 'The meaning, antecedents and outcomes of employee engagement: A narrative synthesis'. International Journal of Management Reviews, 19: 1, 31-53.

Bakker, A.B. and Demerouti, E. (2007). 'The job demands-resources model: State of the art'. Journal of Managerial Psychology, 22: 3, 309-328.

Bakker, A.B. and Demerouti, E. (2014). 'Job demandsresources theory', in P.Y. Chen and C.L. Cooper (eds), Work and Wellbeing: Wellbeing: A Complete Reference Guide, Volume III, UK: John Wiley and Sons, Inc, 37-64.

Bakker, A.B., Hakanen, J.J., Demerouti, E. and Xanthopoulou, D. (2007). 'Job resources boost work engagement, particularly when job demands are high'. Journal of Educational Psychology, 99: 2, 274-284.

Barkhuizen, N., Rothmann, S. and Van de Vijver, F.J.R. (2014). 'Burnout and work engagement of academics in higher education institutions: Effects of dispositional optimism'. Stress and Health, 30: 4, 322-332.

Berscheid, E. (2010). 'Love in the fourth dimension'. Annual Review of Psychology, 61: 1-25.

Billot, J. (2010). 'The Imagined and the Real: Identifying the Tensions for Academic Identity'. Higher Education Research and Development, 29: 6, 709721.

Bowen, D.E. and Ostroff, C. (2004). 'Understanding HRM-firm performance linkages: The role of the 'strength' of the HRM system'. Academy of 
Management Review, 29: 2, 203-221.

Boyne, G.A. (2002). 'Public and private management: What's the difference?'. Journal of Management Studies, 39: 1, 97-122.

Braun, V. and Clarke, V. (2006). 'Using thematic analysis in psychology'. Qualitative Research in Psychology, 3: 2, 77-101.

Byrne, Z.S., Peters, J.M. and Weston, J.W. (2016). 'The struggle with employee engagement: Measures and construct clarification using five samples'. Journal of Applied Psychology, 101: 9, 1201-1227.

Central Statistics Office. (2016). 'EHQ10: Public sector employment and earnings by sub sector, quarter and statistics'. CSO. http://www.cso.ie/px/ pxeirestat/Statire/SelectVarVal/saveselections.asp [Accessed 24 February 2016].

Christian, M.S., Garza, A.S. and Slaughter, J.E. (2011). 'Work engagement: A quantitative review and test of its relations with task and contextual performance'. Personnel Psychology, 64: 1, 89-136.

Clarke, C., Knights, D. and Jarvis, C. (2012). 'A labour of love? Academics in business schools'. Scandinavian Journal of Management, 28: 1, 5-15.

Clarke, M., Kenny, A. and Loxley, A. (2015). Creating a Supportive Working Environment for Academics in Higher Education: Country Report Ireland, Dublin: TUI and IFUT.

Coetzee, S. and Rothmann, S.E. (2005). 'Work engagement of employees at a higher education institution in South Africa'. Southern African Business Review, 9: 3, 23-34.

Consiglio, C., Borgogni, L., Di Tecco, C. and Schaufeli, W.B. (2016). 'What makes employees engaged with their work? The role of self-efficacy and employee's perceptions of social context over time'. Career Development International, 21: 2, 125-143.

Conway, E., Monks, K., Fu, N., Alfes, K. and Bailey, C. (2015). 'Demands or resources? The relationship between HR practices, employee engagement, and emotional exhaustion within a hybrid model of employment relations'. Human Resource Management. [Online]. DOI: 10.1002/hrm.21691.

Conway, J.M. and Lance, C.E. (2010). 'What reviewers should expect from authors regarding common method bias in organizational research'. Journal of Business Psychology, 25:3, 325-334.

Department of Public Expenditure and Reform. (2013). 'LRC Proposals Public Service Stability Agreement 2013-2016: The Haddington Road Agreement May 2013'. Department of Public Expenditure and Reform. http://www.per.gov.ie/en/haddington-roadagreement/
Eisenberger, R., Huntington, R., Hutchison, S. and Sowa, D. (1986). 'Perceived Organisational Support'. Journal of Applied Psychology, 71: 3, 500-507.

Farndale, E., Beijer, S.E., Van Veldhoven, M., Kelliher, C. and Hope-Hailey, V. (2014). 'Work and organisation engagement: Aligning research and practice'. Journal of Organizational Effectiveness: People and Performance, 1: 2, 157-176.

Farndale, E., Van Ruiten, J., Kelliher, C. and HopeHailey, V. (2011). 'The influence of perceived employee voice on organizational commitment: An exchange perspective'. Human Resource Management, 50: 1, 113-129.

Fletcher, L. and Robinson, D. (2014). 'Measuring and understanding employee engagement', in C. Truss, R. Delbridge, K. Alfes, A. Shantz and E. Soane (eds), Employee Engagement in Theory and Practice, UK: Routledge, pp.273-290.

Fredrickson, B.L. (2013). 'Positive emotions broaden and build', in: P. Devine, and A. Plant (eds), Advances in Experimental Social Psychology, Vol. 47, Burlington: Academic Press, pp.1-53.

Freeney, Y. and Fellenz, M.R. (2013a). 'Work engagement as a key driver of quality of care: A study with midwives'. Journal of Health Organization and Management, 27: 3, 330-349.

Freeney, Y. and Fellenz, M. (2013b). 'Work engagement, job design and the role of the social context at work: Exploring antecedents from a relational perspective'. Human Relations, 66: 11, 1427-1445.

Gatenby, M., Soane, E., Alfes, K., Rees, C. and Truss, K. (2009). 'Harnessing Employee Engagement in UK Public Services'. Paper Presented at 10th Public Management Research Association (PRMA) Conference, Columbus, US, 01-03 October 2009.

Ghosh, P., Rai, A. and Sinha, A. (2014). 'Organizational justice and employee engagement'. Personnel Review, 43: 4, 628-652.

Greenleaf, R.K. (1977). Servant Leadership. A Journey into the Nature of Legitimate Power and Greatness, Mahwah: Paulist Press.

Haggerty, J. and Wright, P. (2009). 'Strong situations and firm performance: A proposed Recconceptualization of the role of the HR function', in A. Wilkinson, N. Bacon, T. Redman and S. Snell, (eds), The Sage Handbook of Human Resource Management, London: Sage,100-114.

Hakanen, J.J., Bakker, A.B. and Schaufeli, W.B. (2006). 'Burnout and work engagement among teachers'. Journal of School Psychology, 43: 6, 495-513.

Hakanen, J.J. and Koivumäki, J. (2014). 'Engaged or exhausted - how does it affect dentists' clinical 
productivity'. Burnout Research, 1: 1, 12-18.

Hakanen, J.J. and Peeters, M. (2015). 'How do work engagement, workaholism, and the work-to-family interface affect each other? A 7-year follow-up study'. Journal of Occupational and Environmental Medicine, 57: 6, 601-609.

Harter, J.K., Schmidt, F.L., Agrawal, S. and Plowman, S.K. (2013). 'The Relationship Between Engagement at Work and Organizational Outcomes: 2012 Q $^{12}$ Meta-Analysis'. Technical Paper. http://www.gallup. com/services/177047/q12-meta-analysis.aspx.

Higgins, C. (2015). 'Train Dispute - Increase in 'Driving' Hours Key to Resolution'. IRN 40, 5th November 2015.

Higgins, C. (2016). 'Luas Dispute Reaches Make-OrBreak Stage as Easter Strikes Planned'. IRN 09, 3rd March 2016.

House, R.J. and Mitchell, T.R. (1974). 'Path-goal theory of leadership'. Journal of Contemporary Business, $1,:$ 81-98.

Jeve, Y.B., Oppenheimer, C. and Konje, J. (2015). 'Employee engagement within the NHS: A crosssectional study'. International Journal of Health Policy and Management, 4: 2, 1-6.

Jones, N. and Sambrook, S. (2016). 'Employee engagement in the public sector: What needs to change?', in D. Blackman, S. Teo and M. O'Donnell (eds), Human Capital Management Research: Influencing Practice and Process, UK: Edward Elgar, pp.31-45.

Kahn, W.A. (1990). 'Psychological conditions of personal engagement and disengagement at work'. Academy of Management Journal, 33: 4, 692-724.

Kelliher, C., Hope-Hailey, V. and Farndale, E. (2014). 'Employee engagement in multinational companies', in C. Truss, R. Delbridge, K. Alfes, A. Shantz and E. Soane (eds), Employee Engagement in Theory and Practice, UK: Routledge, pp.180194.

Kenny, A. (2015). 'Study on Work-Related Stress: Experience of Academics in the Institute of Technology Sector 2014'. DIT Level3, Issue 13, June 2015.

Klassen, R.M., Frenzel, A.C. and Perry, N.E. (2012). 'Teachers' relatedness with students: An underemphasised component of teachers' Basic Psychological Needs'. Journal of Educational Psychology, 104: 1, 150-165.

Knies, E., Boselie, P., Gould-Williams, J. and Vandenabeele, W. (2015). 'Special issue of international journal of human resource management: Strategic human resource management and public sector performance'. The International Journal of Human Resource Management, 26: 3, 421-424.

Kurtessis, J.N., Eisenberger, R., Ford, M.T., Buffardi, L.C., Stewart, K.A. and Adis, C.S. (2015). 'Perceived organizational support: A metaanalytic evaluation of organizational support theory'. Journal of Management, [Online]. DOI: 10.1177/0149206315575554.

Levinson, H. (1965). 'Reciprocation: The relationship between man and organization'. Administrative Science Quarterly, 4: 9, 370-390.

Li, M., Wang, Z., You, X. and Gao, J. (2015). 'Value congruence and teachers' work engagement: The mediating role of autonomous and controlled motivation'. Personality and Individual Differences, 80: 113-118.

Lorente, L.P., Salanova, M.S., Martínez, I.M. and Schaufeli, W. (2008). 'Extension of the job demands-resources model in the prediction of burnout and engagement among teachers over time'. Psicothema, 20: 3, 354-360.

Malhotra, N.K. and Birks, D.F. (2006). Marketing Research: An Applied Approach, 2nd European Edition, England: Pearson Education Limited.

Malinen, S., Wright, S. and Cammock, P. (2013). 'What drives organisational engagement? A case study on trust, justice perceptions and withdrawal attitudes'. Evidence-based HRM: A Global Forum for Empirical Scholarship, 1: 1, 96-108.

McDermott, A.M., Conway, E., Rousseau, D.M. and Flood, P. (2013). 'Promoting effective psychological contracts through leadership: The missing link between HR strategy and performance'. Human Resource Management, 52: 2, 289-310.

Myers, J.E. and Shurts, M. (2002). 'Measuring positive emotionality: A review of instruments assessing love'. Measurement and Evaluation in Counseling and Development, 34:4 238-254.

Perry, J.L. (1996). 'Measuring public service motivation: An assessment of construct reliability and validity'. Journal of Public Administration and Theory, 6: 1, 5-22.

Perry, J.L., Hondeghem, A., and Recascino Wise, L. (2010). 'Revisiting the motivational bases of public service: Twenty years of research and an agenda for the future'. Public Administration Review, 70: 5, 681-690.

Podsakoff, P.M., MacKenzie, S.B., Lee, J.-Y. and Podsakoff, N.P. (2003). 'Common method biases in behavioural research: A critical review of the literature and recommended remedies'. Journal of Applied Psychology, 88: 5, 869-903. 
Purcell, J. and Hutchinson, S. (2007). 'Front line managers as agents in the HRM-performance causal chain: Theory, analysis and evidence'. Human Resource Management Journal, 17: 1, 3-20.

Redman, T. and Snape, Ed. (2005). 'Unpacking commitment: Multiple loyalties and employee behaviour'. Journal of Management Studies, 42: 2, 301-328.

Reis, H.T., Maniaci, M.R. and Rogge, R.D. (2014). 'The expression of compassionate love in everyday compassionate acts'. Journal of Social and Personal Relationships, 31: 5, 651-676.

Reissner, S. and Pagan, V. (2013). 'Generating employee engagement in a public-private partnership: Management communication activities and employee experiences'. International Journal of Human Resource Management, 24: 14, 27412759.

Ritz, A., Shantz, A., Alfes, K. and Arshoff, A.S. (2012). 'Who needs leaders the most? The interactive effect of leadership and core self-evaluations on commitment to change in the public sector'. International Public Management Journal, 15: 2, 160-185.

Rothmann, S. and Jordaan, G.M.E. (2006). 'Job demands, job resources and work engagement of academic staff in South African higher education institutions'. SA Journal of Industrial Psychology, 32: 4, 87-96.

Rubin, Z. (1970). 'Measurement of romantic love'. Journal of Personality and Social Psychology, 16: 2, 265-273.

Runhaar, P., Sanders, K. and Konermann, J. (2013). 'Teachers' work engagement: Considering interaction with pupils and human resources practices as job resources'. Journal of Applied Social Psychology, 43: 10, 2017-2030.

Ryan, R.M. and Deci, E.L. (2000). 'Self-determination theory and the facilitation of intrinsic motivation, social development and well-being'. American Psychologist, 55: 1, 68-78.

Sabey, A.K., Rauer, A.J. and Haselschwerdt, M.L. (2015). 'It's not just words coming from the mouth': The nature of compassionate love among older couples'. Journal of Social and Personal Relationships. [Online]. DOI: 10.1177/0265407515588219.

Saks, A.M. (2006). 'Antecedents and consequences of employee engagement'. Journal of Managerial Psychology, 21: 7, 600-619.

Saks, A.M. and Gruman, J.A. (2014). 'What do we really know about employee engagement?'. Human Resource Development Quarterly, 25: 2, 155-182.
Saunders, M., Lewis, P. and Thornhill, A. (2009). Research Methods for Business Students, 5th edn, Harlow: Pearson.

Schaufeli, W.B. (2014). 'What is engagement', in C. Truss, R. Delbridge, K. Alfes, A. Shantz and E. Soane (eds), Employee Engagement in Theory and Practice, UK: Routledge, pp.15-35.

Schaufeli, W.B. (2015). 'Engaging leadership in the job demands-resources model'. Career Development International, 20: 5, 446-463.

Schaufeli, W.B. and Bakker, A.B. (2003) UWES Utrecht Work Engagement Scale Preliminary Manual [Version 1 November 2003], Utrecht University.

Schaufeli, W.B. and Taris, T.W. (2014). 'A critical review of the job demands-resources model: Implications for improving work and health', in G. Bauer and O. Hämmig (eds), Bridging Occupational, Organizational and Public Health, Dordrecht: Springer, pp.43-68.

Schaufeli, W.B., Salanova, M., González-Romá, V. and Bakker, A.B. (2002). 'The measurement of engagement and burnout: A two sample confirmatory factor analytic approach'. Journal of Happiness Studies. 3: 1, 71-92.

Shantz, A., Alfes, K., and Latham, G.P. (2016). 'The buffering effect of perceived organisational support on the relationship between work engagement and behavioural outcomes. Human Resource Management, 55: 1, 25-38.

Shuck, B. and Wollard, K. (2010). 'Employee engagement and HRD: A seminal review of the foundations'. Human Resource Development Review, 9: 1, 89-110.

Suddaby, R. (2010). 'Editor's comments: Construct clarity in theories of management and organization'. Academy of Management Review, 35: 3, 346-357.

Teachers' Union of Ireland. (2016). 'Lecturers Strike over Funding and Educational Crisis - TUI calls on Department to Engage Meaningfully on Issues'. TUI. http://www.tui.ie/news-events/lecturers-strikeover-funding-and-educational-crisis-tui-callson-department-to-engage-meaningfully-on-keyissues.8047.html.

Teichler, U., Arimoto, A. and Cummings, W. (2013). The Changing Academic Profession: Major Findings of a Comparative Survey, London: Springer.

Townsend, K., Wilkinson, A. and Allan, C. (2012). 'Mixed signals in HRM: The HRM role of hospital line managers'. Human Resource Management Journal, 22: 3, 267-282.

Trépanier, S.G., Fernet, C., Austin, S. and Ménard, J. (2015). 'Revisiting the interplay between burnout 
and work engagement: An exploratory structural equation modelling (ESEM) approach'. Burnout Research, 2: 2, 51-59.

Truss, C. (2013). 'The distinctiveness of HRM in the public sector', in R. Burke, A. Noblet and C. Cooper (eds), HRM in the Public Sector, London: Edward Elgar, 17-36.

Truss, C., Delbridge, R., Alfes, K., Shantz, A. and Soane, E. (2014). 'Introduction', in C. Truss, R. Delbridge, K. Alfes, A. Shantz and E. Soane (eds), Employee Engagement in Theory and Practice, UK: Routledge, pp.1-12.

Vigoda-Gadot, E., Eldor, L. and Schohat, L.M. (2012). 'Engage them to public service: Conceptualization and empirical examination of employee engagement in public administration'. The American Review of Public Administration, 43: 5, 518-538.

Willem, A., De Vos, A. and Buelens, M. (2010). 'Comparing private and public sector employees' psychological contracts: Do they attach equal importance to general work aspects?'. Public Management Review, 12: 2, 275-302.

Winter, R. (2009). 'Academic manager or managed academic? Academic identity schisms in higher education'. Journal of Higher Education Policy and Management, 31: 2, 121-131.

Wright, B.E. (2007). 'Public service motivation: Does mission matter?'. Public Administration Review, 67: 1, 54-64. 